\title{
Simulation and Field Measurement Study on Roof Strata Behavior of Fully Mechanized Caving Face
}

\author{
Weitao Liu, Wencheng Song, Jianning Wang \\ Shandong University of Science and Technology \\ Shandong, 266590, China \\ skdlwt@126.com
}

\begin{abstract}
In order to reveal the related law between strata behavior and rock burst of fully mechanized caving face, this paper discussed the relationship between the distribution of abutment pressure and energy in front of the coal wall of fully mechanized caving mining face from the point of view of energy. Taking 1304 working face in Yangcheng coal mine as background, using numerical simulation of FLAC3D, it also studied the influence range of support pressure, the law of stress concentration and the distribution of residual energy under different positions of the working face at different advancing steps. And combined with the field measurement, it further determined the peak position of the bearing pressure and the range the bearing pressure and the influence of the mining area. The research shows that: (1) the support pressure peak is located in the front of the coal wall $10 \sim 15 \mathrm{~m}$; the obviously influence range of bearing pressure is $60 \mathrm{~m}$; the mining influence range is $120 \mathrm{~m}$; the numerical simulation is basically consistent with the result of field measurement; (2) The distribution of energy difference curve and supporting pressure in front of working face is approximately similar. Near the peak of supporting pressure, the value of energy difference is higher, and rock burst is easy to occur; (3) The support pressure and energy distribution in front of the coal wall are different along the orientation of the working face. Under the same advancing step, the peak value of pressure and peak energy difference of the lower end of the working face is larger than that of the working face, and the upper end is the smallest.
\end{abstract}

$\begin{aligned} & \text { Keywords } \\ & \text { Pressure;Bearing } \\ & \text { Measurement }\end{aligned}$
Pressure;Residual Energy;FLAC3D; Field

\section{INTRODUCTION}

At present, the comprehensive mechanized coal caving mining technology is a new technology based on fully-mechanized mining in the middle and thick coal seam at a time. Compared with the traditional coal mining technology, the thickness of coal seam in fully mechanized caving at a time increases one to several times, and leads to the great changes of distribution law of supporting pressure of working face, mine pressure appear and surrounding rock movement law[1]. When roof , floor strata and coal seam has bump proneness, the strong rock pressure around the stope is very easy to induce the occurrence of dynamic disasters such as rock burst.

Jiachen Wang, Weidong Pan, et al used FLAC ${ }^{3 \mathrm{D}}$ to simulate the mining process of different direct roof thickness in fully mechanized caving face. The research shows that when the thickness of the direct roof is less than $10 \mathrm{~m}$, the first weighting interval of main roof is proportional to its thickness[2]. Mingyue Weng, Jinhai Xu, et al used changes of microseismic practice indirectly reflect pressure behaviors of the working face[3]. Based on similar simulation test, Jinping Zheng, Yanjun Feng, et al simulated the mining process of fully mechanized caving and analyzed the law of roof pressure behavior[4]. According to different geological conditions such as long, shallow buried, large inclined angle, thick coal seam, etc, many scholars have explored the law of pressure behavior of fully mechanized caving[5-17]. In order to study the law of pressure behavior and rock burst, taking 1304 working face of Yangcheng coal mine as the background and using FLAC ${ }^{3 D}$ numerical simulation and field measurement, the author studied the relationship between the support pressure distribution and energy change in the front of the fully mechanized caving face with different advancing distance. The results show that the result of the numerical simulation is basically consistent with that of the field measurement, and it has achieved good application results.

\section{THEORETICAL CRITERION OF ROCK BURST}

According to the minimum energy principle of dynamic damage of rock mass, no matter in one-dimensional and twodimensional or three-dimensional stress state, the energy required by the dynamic failure of rock mass is always equal to the energy consumed by the failure of one dimensional stress state[18]. Therefore, both uniaxial compression failure and shear failure, its damage conditions are as follows: stress than the uniaxial compressive strength and shear strength. That is, $\sigma>\sigma_{c}$ or $\tau>\tau_{c}$. The corresponding energy consumption standards can be expressed as:

$$
E_{C}=\frac{\sigma_{C}}{2 E} \text { or } E_{C}=\frac{\tau_{C}}{2 G}
$$

In the type: $E_{\mathrm{c}}$ stands for the energy consumed by the failure of one dimensional stress state; $\sigma_{c}$ stands for uniaxial compressive strength; $\tau_{c}$ stands for uniaxial shear strength; $E$ is elastic modulus; $G$ is bulk modulus.

Generally, rockburst occurs in the coal and rock mass in brittle state, at this time, coal and rock in triaxial state of stress, has accumulated a large amount of elastic strain energy. According to the generalized Hooke theorem, the formula for 
calculating the elastic strain energy of coal in the three direction stress state is as following:

$$
E_{0}=\frac{\sigma_{1}^{2}+\sigma_{2}^{2}+\sigma_{3}^{2}-2 \mu\left(\sigma_{1} \sigma_{2}+\sigma_{1} \sigma_{3}+\sigma_{2} \sigma_{3}\right)}{2 E}
$$

In the type: $E_{0}$ stands for the elastic strain energy of coal in the three direction stress state; $E$ is elastic modulus; $\mu$ is poisson ratio; $\sigma_{1}$ is the first principal stress; $\sigma_{2}$ is the second principal stress; $\sigma_{3}$ is the third principal stress.

According to the energy theory, when the energy $E_{0}$ released by the instability of the mechanical equilibrium state of the coal and its surrounding rock system is larger than the energy $E_{\mathrm{c}}$ consumed in the mechanical equilibrium state, it will happen rockburst, and the starting energy criterion of rock burst can be expressed as:

$$
E_{0}-E_{c}>0
$$

In the type: $E_{0}$ stands for the energy released by the instability of the mechanical equilibrium state of the coal and its surrounding rock system; $E_{\mathrm{c}}$ stands for the energy consumed in the mechanical equilibrium state.

From the above type, if the coal rock mass is given, $E$ and $\mu$ are given. Therefore, the elastic strain energy stored in the study area can be determined by the principal stress of the position. When $E_{0}>E_{c}$, the front of the coal wall may occur rock burst, the greater the residual energy $E_{0}-E_{c}$, the greater the impact of the risk.

\section{A) Numerical simulation}

1) Engineering geological condition

No. 3 coal seam is the main coal seam of 1304 working face in Yangcheng coal mine. It is located at the level of -650 $\mathrm{m}$, the thickness of coal seam is $7.0 \sim 8.2 \mathrm{~m}$, the average thickness is $7.5 \mathrm{~m}$, the dip angle of coal seam is 17 21 degrees, the average dip angle is 19 degrees. Inclined length of working face is $180 \mathrm{~m}$, and the strike length is $800 \mathrm{~m}$. Coal mining technology is strike longwall fully mechanized top coal caving, full height of coal seam at one time and full caving method. Coal cutting height is $2.7 \mathrm{~m}$, Coal caving height is $4.8 \mathrm{~m}$, Coal mining and caving ratio is $1: 1.8$, Coal caving step distance is $0.8 \mathrm{~m}$. The way of coal caving is to cut the coal once and then follow the coal caving once. The working face is a single structure, and the geological conditions are relatively simple. Lithology of coal seam and roof and floor, as shown in Figure 1.

\section{2) Model building}

According to the mining geological conditions, the physical and mechanical parameters of the rock strata group and strata comprehensive histogram of the research area of Yangcheng coal mine, fully mechanized caving mining geological model of 1304 working face is built, as shown in

\begin{tabular}{|c|c|c|c|}
\hline Columnar & Rock (coal) layer name & Thickness(m) & Characterization of rock strata \\
\hline 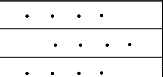 & Fine sandstone & 5.0 & $\begin{array}{l}\text { Gray white, fine - grained structure, the development of the top cracks, } \\
\text { mainly quartz, feldspar. }\end{array}$ \\
\hline $\begin{array}{ll} & \cdot \\
\cdot & \cdot \\
\end{array}$ & Gritrockn & 3.1 & Gray white, fine sandstone and silty sandstone. \\
\hline $\begin{array}{lll}-\cdot \cdot \cdot- \\
-\cdot \cdot \cdot \cdot- \\
\end{array}$ & Silty sandstone & 3.0 & Light gray, fine sandstone micro strip. \\
\hline $\begin{array}{ll}\cdot \cdot \cdot & \cdot \\
\cdot \cdot \cdot & \cdot \\
\cdot \cdot \cdot & \cdot\end{array}$ & Medium sand & 3.2 & $\begin{array}{l}\text { Gray white, layered structure, the upper square calcite veinlets, mainly } \\
\text { composed of quartz, siliceous cementation. }\end{array}$ \\
\hline $\begin{array}{l}\cdot \cdot \cdot \cdot \cdot \\
\cdot \cdot \cdot \cdot \\
\end{array}$ & Fine sandstone & 6.8 & The grey light grey, with siltstone, bedding is developed. \\
\hline \begin{tabular}{|c|}
$\cdot \cdot \cdot \cdot$ \\
$-\cdot \cdot \cdot-$ \\
-----
\end{tabular} & Silty sandstone & 1.5 & $\begin{array}{l}\text { Light gray, horizontal bedding, clip pyrite nodules and pyrite veins, } \\
\text { brown diamond iron stripes. }\end{array}$ \\
\hline & Mudstone & 1.9 & Gray white, containing plant fossils, calcareous cementation. \\
\hline & No.3 Coal Seam & 7.5 & With bright coal, brown black streak, thick $7.5 \mathrm{~m}$. \\
\hline $\begin{array}{ll}-----1 \\
-\cdot \cdot \cdot \cdot- \\
-\cdot \cdot \cdot-1\end{array}$ & Mudstone & 1.2 & Black, massive, plant root fossil. \\
\hline \begin{tabular}{|l|l|}
$-\cdot \cdot \cdot-$ \\
$-\cdot \cdot \cdot-$ \\
\end{tabular} & Silty sandstone & 8.5 & $\begin{array}{l}\text { Gray, light gray fine sandstone thin clip, wavy bedding, clip siderite } \\
\text { concretions. }\end{array}$ \\
\hline \begin{tabular}{|c|}
$-\cdot \cdot \cdot-$ \\
------ \\
------
\end{tabular} & Mudstone & 4.3 & $\begin{array}{l}\text { There are dark brown gray component containing calcite, clay, rock } \\
\text { joints is broken. }\end{array}$ \\
\hline $\begin{array}{c}------- \\
\cdot \cdot \cdot \cdot \\
\end{array}$ & Fine sandstone & 3.5 & Light grey, with oblique bedding, visible level mica. \\
\hline \begin{tabular}{r|}
$\cdot \cdot \cdot \cdot \cdot$ \\
$-\cdot \cdot \cdot-$ \\
$-\cdot \cdot \cdot-$
\end{tabular} & Silty sandstone & 3.1 & $\begin{array}{l}\text { Gray, with pyrite nodules and pyrite veins, horizontal bedding, } \\
\text { brown diamond iron stripes. }\end{array}$ \\
\hline $\begin{array}{l}-\cdot \cdot \cdot- \\
\cdot \cdot \cdot \\
-\cdot \cdot \cdot-\end{array}$ & Fine sandstone & 2.3 & $\begin{array}{l}\text { Light grey, dark grey siltstone interbeds with layered, wavy } \\
\text { bedding, containing siderite concretions. }\end{array}$ \\
\hline $\begin{array}{ll}-\cdot \cdot \cdot- \\
-\cdot \cdot \cdot-\end{array}$ & Silty sandstone & 5.2 & $\begin{array}{l}\text { Dark gray, with fine sandstone bands and thin, wavy bedding, clip } \\
\text { siderite concretions, containing fossil plants. }\end{array}$ \\
\hline
\end{tabular}
Figure 2.

Fig.1. Strata comprehensive histogram 


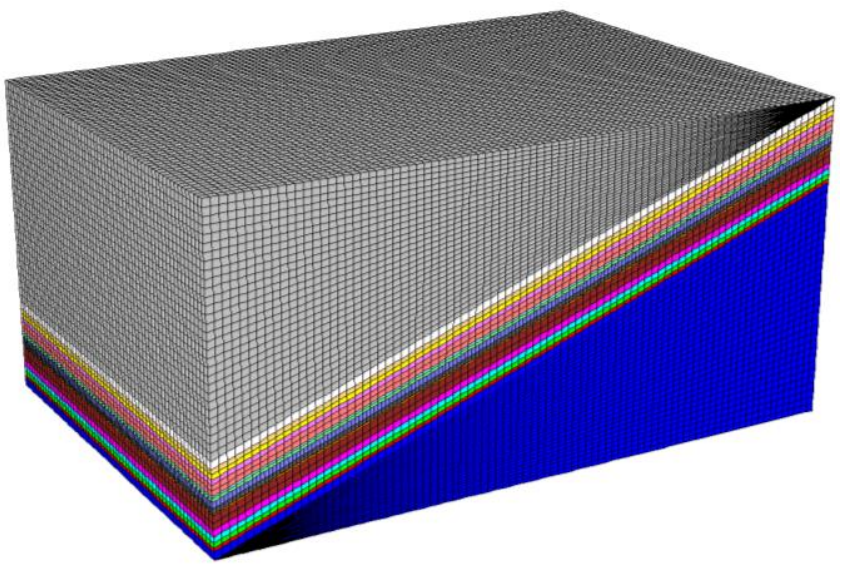

Fig.2. FLAC ${ }^{3 \mathrm{D}}$ numerical model

Model length is $430 \mathrm{~m}$, width is $300 \mathrm{~m}$, height is $260 \mathrm{~m}$; The front and back boundaries and the left and right boundary of the model are constrained by the horizontal direction displacement; The upper boundary layer is simplified to 14.4 MPa uniform load, and the bottom boundary is imposed with full constraint. The direction of the working face length is 330 $\mathrm{m}$, inclined length is $180 \mathrm{~m}$, and coal seam excavation height is $7.5 \mathrm{~m}$, excavation length along strike at every step is $10 \mathrm{~m}$. Considering the boundary effect, mining start and stop line of working face from the left and right boundaries of the model is $50 \mathrm{~m}$; The width of roadway protection pillar before and after the model boundaries is respectively $60 \mathrm{~m}$.

According to the rock mechanics parameter test, the physical and mechanical parameters of each rock layer in the model, as shown in table 1.

B) Monitoring scheme design

By monitoring the support pressure within $80 \mathrm{~m}$ in front of coal wall with different advancing distance, to understand the distribution range of front abutment pressure distribution and Law of stress concentration in front of the working face. By monitoring the support pressure within $80 \mathrm{~m}$ in front of coal wall with different positions along the working face in the direction of inclination, to reveal the change of supporting pressure. By monitoring the energy change in front of the coal wall, to explore the influence of mining on the working face of fully mechanized caving mining face from the point of view of energy. The monitoring points are arranged according to the following scheme.

(1)Along the inclined direction of working face, respectively arrange 3 rows monitoring lines in the roof strata of the upper end, middle and lower end of the working face.

(2)Along the advancing direction of working face, the spacing of monitoring point in each monitoring line is $2.5 \mathrm{~m}$, to simulate support pressure distribution within $80 \mathrm{~m}$ in front of working face when the working face is pushed to the $10 \mathrm{~m}$, $30 \mathrm{~m}, 50 \mathrm{~m}, 70 \mathrm{~m}, 90 \mathrm{~m}$ and $110 \mathrm{~m}$.

Simulation results and analysis

(1) support pressure distribution at different positions along inclined direction of the working face. Support pressure distribution of the middle and two end heads of the working face within $80 \mathrm{~m}$ is shown in Figure 3. It can be seen from the figure:

a. The front abutment pressure of coal face is a process from formation to development, and finally to the stability. With the continuous advancing of the working face, the front abutment pressure peak is gradually increased, and the risk of the rockburst is increasing.

b. Under the same advancing distance, due to the influence of inclination angle and two roadway of the working face, at different positions along the working face, the peak value of the support pressure is different. The bearing pressure of lower end of working face is bigger, the middle is the second, the

TABLE1 Physical and Mechanical Properties Calculation Index of Rock Group

\begin{tabular}{|c|c|c|c|c|c|c|}
\hline Lithology & $\begin{array}{l}\text { Bulk density } \\
\qquad / k N \cdot m^{-3}\end{array}$ & $\begin{array}{l}\text { Bulk modulus } \\
\qquad / G P a\end{array}$ & $\begin{array}{c}\text { Shear } \\
\text { modulus } \\
\text { /GPa }\end{array}$ & $\begin{array}{l}\text { Cohesion } \\
\quad / \mathrm{MPa}\end{array}$ & $\begin{array}{c}\text { Friction angle } \\
/\left({ }^{\circ}\right)\end{array}$ & $\begin{array}{c}\text { Tensile strength } \\
/ \mathrm{MPa}\end{array}$ \\
\hline Fine sandstone & 27 & 23 & 12 & 7.5 & 32 & 2.2 \\
\hline Gritrock & 26.5 & 18 & 10.5 & 4.9 & 36 & 2.8 \\
\hline Silty sandstone & 28 & 15.6 & 10.8 & 7.2 & 44 & 5.0 \\
\hline Medium sand & 25 & 21 & 12 & 7.3 & 42 & 3.9 \\
\hline Fine sandstone & 27 & 23 & 12 & 7.5 & 32 & 2.2 \\
\hline Silty sandstone & 28 & 15.6 & 10.8 & 7.2 & 44 & 5.0 \\
\hline Mudstone & 26 & 16 & 9.8 & 3.3 & 30 & 1.5 \\
\hline No.3 Coal Seam & 14.8 & 2.9 & 1.65 & 3.5 & 30 & 1.9 \\
\hline Mudstone & 26 & 16 & 9.8 & 3.3 & 30 & 1.5 \\
\hline Silty sandstone & 28 & 15.6 & 10.8 & 7.2 & 44 & 5.0 \\
\hline Mudstone & 26 & 16 & 9.8 & 3.3 & 30 & 1.5 \\
\hline Fine sandstone & 27 & 23 & 12 & 7.5 & 32 & 2.2 \\
\hline Silty sandstone & 28 & 15.6 & 10.8 & 7.2 & 44 & 5.0 \\
\hline Fine sandstone & 27 & 23 & 12 & 7.5 & 32 & 2.2 \\
\hline Silty sandstone & 28 & 15.6 & 10.8 & 7.2 & 44 & 5.0 \\
\hline
\end{tabular}




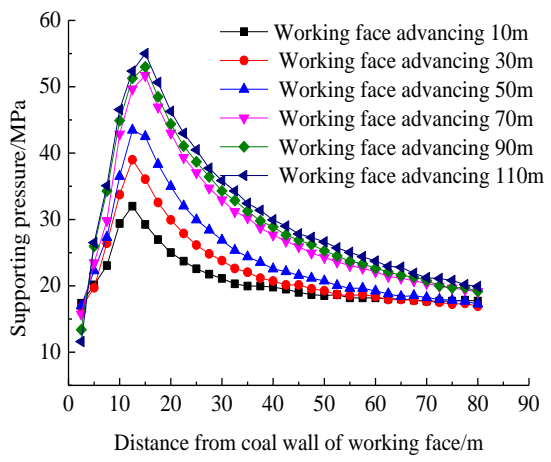

(a) The upper end of working face

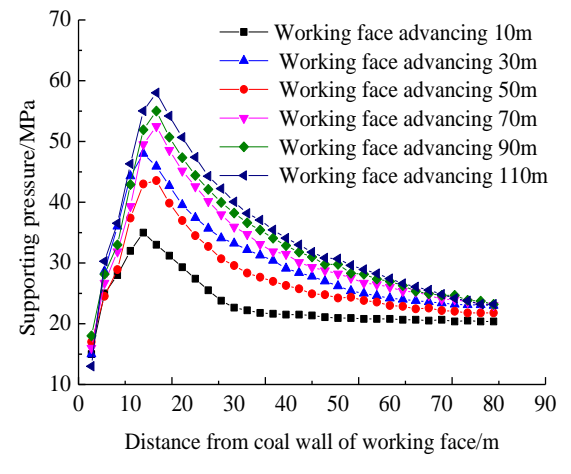

(b) The middle of working face

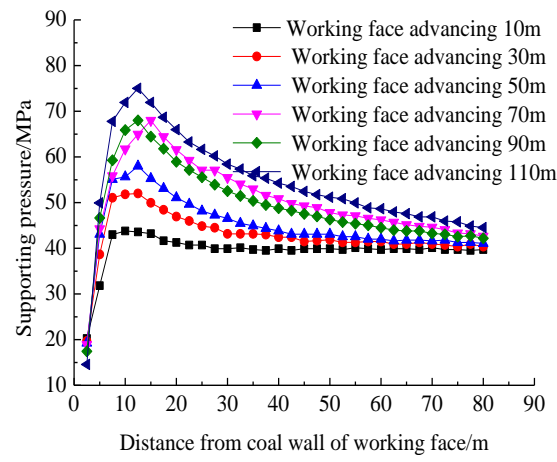

(c) The lower end of working face

Fig.3 Support pressure distribution in $80 \mathrm{~m}$ range of working face

upper end is the smallest.

c. In the front of the working face coal wall $0 \mathrm{~m} \sim 60$ range, the change of support pressure is more obvious. After more than $60 \mathrm{~m}$, the curve of supporting pressure is relatively gentle. Therefore, the influence range of abutment pressure is about $60 \mathrm{~m}$.

d. With the advance of working face, the peak position of supporting pressure is slightly changed. At different positions of the working face, the peak position of the support pressure is different, and its peak position is mostly concentrated in the b. With different positions along the inclined direction, the remaining energy concentration in the front of the coal wall is different. In general, the energy concentration of the lower end is greater than that in the middle, and the upper end of the head is the smallest. However, considering the influence of working face to pressure, the supporting of the upper end can not be ignored.

c. The remaining energy values of the working face under different advancing distances are constantly changing. With the continuous advancement of the working surface, the

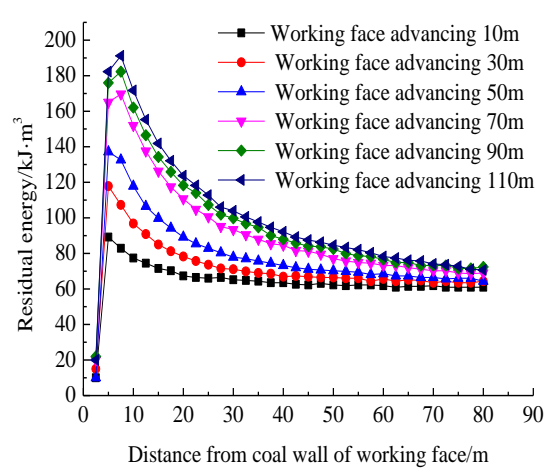

(a) The upper end of working face

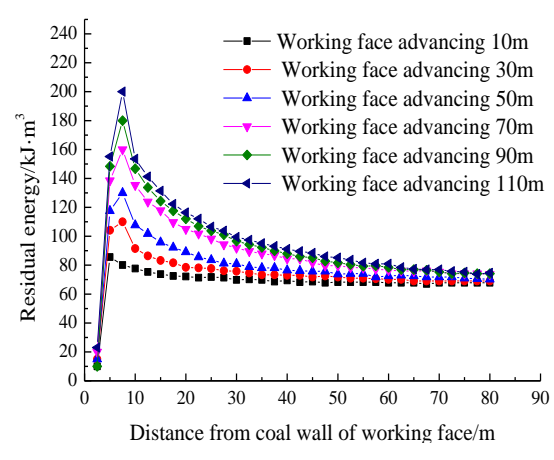

(b) The middle of working face

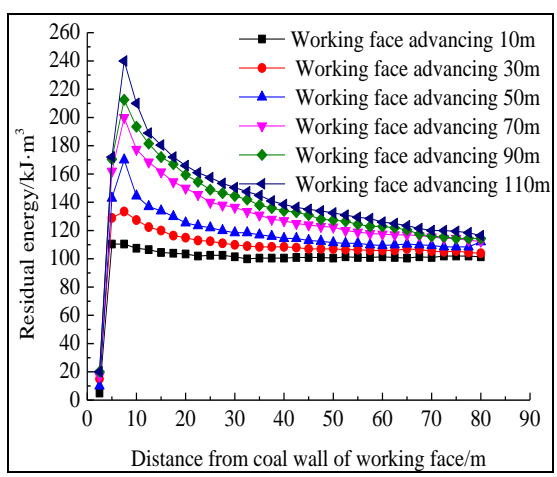

(c) The lower end of working face

Fig.4 Residual energy distribution in $80 \mathrm{~m}$ range of working face

front of the coal wall between $10 \mathrm{~m} \sim 15 \mathrm{~m}$.

(2) Distribution of residual energy at different positions of the working face under different advancing distance. By fish programming language owning to $\mathrm{FLAC}^{3 \mathrm{D}}$, running and exporting the residual energy value $E_{0^{-}} E c$ in front of the working face $80 \mathrm{~m}$, and making the distribution of residual energy at the upper end, middle and lower end of working face, as shown in Figure 4.

It can be seen from the figure:

a. The trend of energy distribution curve is generally consistent with the bearing pressure distribution in front of the working face. Both of them showed increased first and then decreased. Near the peak of the supporting pressure, the residual energy is higher, and the impact is more dangerous. residual energy peak is increasing, and the risk of impact is increasing.

d. With the continuous advancement of the working surface, the energy range of the coal wall in front of the working face is increasing. When the working face advancing $10 \mathrm{~m}$, the influence range is about $20 \mathrm{~m}$, and when the working face advancing $130 \mathrm{~m}$, the influence range expands to $60 \mathrm{~m}$. This is consistent with the distribution law of abutment pressure.

\section{FIELD MEASUREMENT}

\section{A) Design of measurement scheme}

Through the observation on both sides of the roadway of monomer hydraulic prop live column and monomer live 
column shrinkage, it can further study the peak position of the supporting pressure of the working face, the influence range of the support pressure and the influence of the mining area. Specific programs are as follows:

(1) Measurement scheme of supporting pressure peak position

In the two roadway, a measuring point is set at every $5 \mathrm{~m}$ from the coal wall, and a total of 10 measuring points are arranged. The arrangement of the measuring points is shown in Figure 5. Workers in every class can measure the monomer shrinkage. When the working face is pushed to the nearest measuring point near the coal wall, the pressure gauge will be moved to $5 \mathrm{~m}$, which is farthest from the coal wall of the working face, and a new measuring point will be set up here.

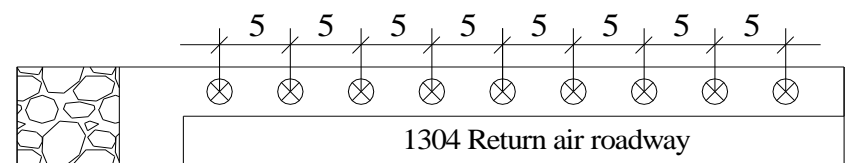

Coal wall of working face

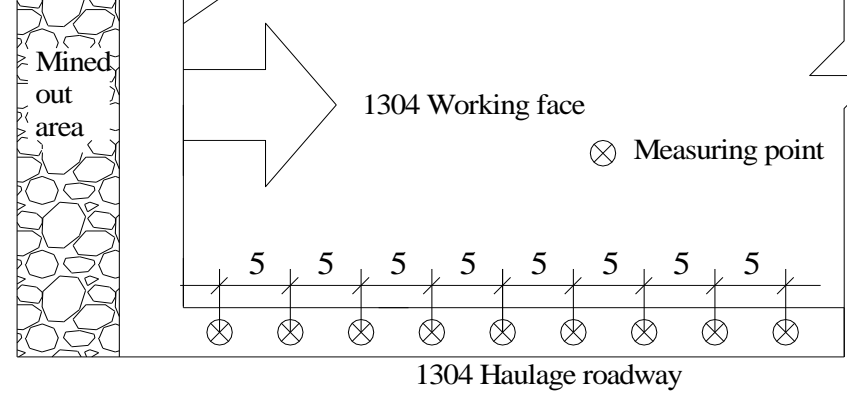

Fig.5 Measurement scheme of supporting pressure peak position

(2) Measurement scheme of bearing pressure obviously influence range

A measuring point is set at every $8 \mathrm{~m}$ from the coal wall in two roadway. As shown in Figure 6, Each measuring point is fitted with an electronic pressure gauge. The pressure gauge is installed in the side near the solid coal, and The pressure gauge can record the measuring point of coal wall and the distance between the monomer column volume and pressure value. When the working face is pushed to the nearest measuring point near the coal wall, the pressure gauge is moved to the most remote measuring point of the coal wall of the working face, and a new measuring point is set up here.

(3) Measurement scheme of mining influence range

A measuring point is set at every $5 \mathrm{~m}$ from the coal wall in return air roadway, a total of 30 measuring points are arranged. The arrangement of the measuring points is shown in Figure 7. Workers of every class can measure the shrinkage of the plunger monomer.

A) Measured results and analysis

(1) The measured results of the peak position of the support pressure

In two the roadway, within the range of $0 \sim 20 \mathrm{~m}$, single live shrinkage column are generally larger, and more than $20 \mathrm{~m}$, shrinkage is gradually reduced. Taking into the working face of coal wall in front of the $0 \sim 10 \mathrm{~m}$ range account, coal generally enter the plastic zone, and in the stress reduction zone. Therefore, the peak position of the supporting pressure can be determined in the front of the working face 10 15 m.

(2) The measured results of bearing pressure and mining influence range

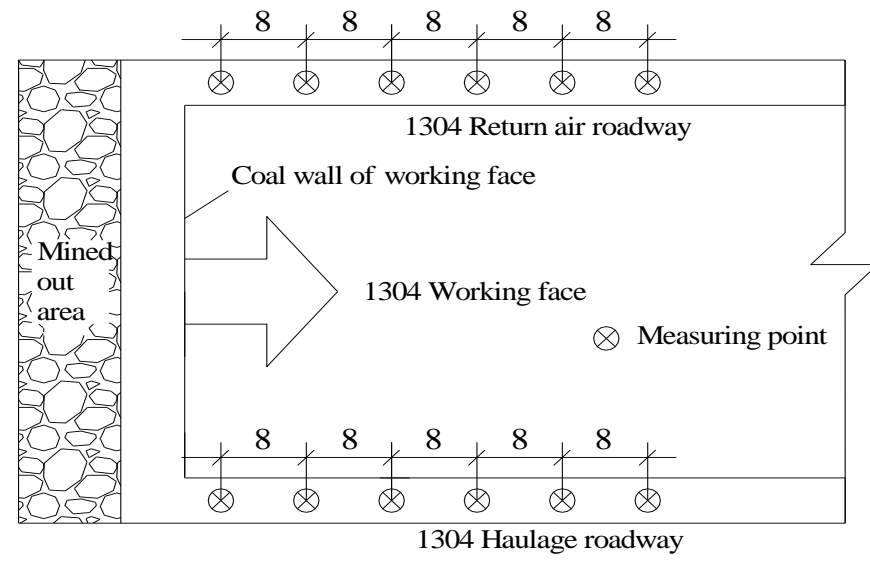

Fig.6 Measurement scheme of supporting pressure influence range

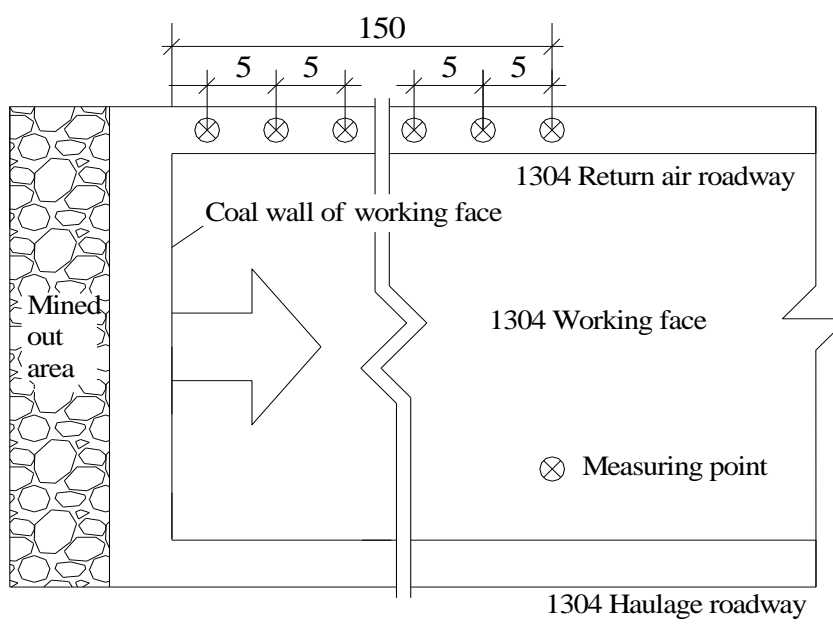

Fig.7 Measurement scheme of mining influence range

In the range of about $20 \mathrm{~m}$ from the coal wall, single column live shrinkage is large, numerical value is about $60 \mathrm{~mm}$. From the coal wall outside $20 \mathrm{~m}$, shrinkage of the plunger is obviously reduced. It is further confirmed that the position of the support pressure peak in front of the coal wall $15 \sim 20 \mathrm{~m}$. In the range of about $60 \mathrm{~m}$ from the coal wall, single column live shrinkage is more obvious. In the range of about $60 \mathrm{~m}$ from the coal wall, single column live shrinkage is smaller. More than $120 \mathrm{~m}$, single live shrinkage cylinder is close to 0 . This shows that the bearing pressure is obviously affected by the range of about $60 \mathrm{~m}$, and the mining influence range is about $120 \mathrm{~m}$ 


\section{CONCLUSION}

(1) The numerical simulation shows that, with the continuous advance of working face, the peak value of abutment pressure in front of the working face is increasing.The degree of stress concentration is increasing, and the influence of the supporting pressure range becomes larger,and the working face supporting pressure peak is located in the front of the coal wall $10 \mathrm{~m} \sim 15 \mathrm{~m}$ position. The bearing pressure obviously affects the range of $60 \mathrm{~m}$. The distribution of energy difference curve and abutment pressure distribution in front of working face is approximately the same, which is close to the peak of supporting pressure, the energy difference is higher, and the impact is more dangerous.

(2) According to the field measurement, it is showed that the support pressure peak position is located in the range of $10 \mathrm{~m} \sim 15 \mathrm{~m}$ front of the coal wall, the bearing pressure obviously affects the range of $60 \mathrm{~m}$, and the mining influence range is $120 \mathrm{~m}$, which is basically consistent with the numerical simulation results.

(3) The support pressure and energy distribution in front of the coal wall are different at different positions in the inclined plane.The same push distance along the face tendency, to the lower end of the coal wall front abutment pressure peak value and energy difference peak is greater than the middle of working face, the upper end head is minimal.However, this does not indicate that the upper end of the head impact risk is small.By the roof to pressure and support the impact of inequality, the top of the head with a strong pressure to the degree of risk is still very high.

\section{ACKNOWLEDGEMENT}

In this paper, the research was sponsored by the National Natural Science Foundation of China (Project No. 51274135), the Joint Research Fund for Overseas Natural Science of China (Project No. 51428401) and the State Key Program of National Natural Science of China (Project No. 51034003)

\section{REFERENCES}

[1] Tan Yunliang, Wu Shiliang, Yin Zengde, et al. Ground pressure and strata control[M]. Beijing: China Coal Industry Publishing House, 2008.

[2] Wang Jiachen, Pan Weidong, Li Cheng. 3D numerical simulation of top coal caving with hard roof in Gequan mine[J]. Journal of Mining \& Safety Engineering, 2008, 25(3): 272-276.

[3] Weng Mingyue, Xu Jinhai, Li Chong. Relationship of coal and rock damage, underground behavior and methane gushing in fully-mechanized caving mining face[J]. Journal of China Coal Society, 2011, 36(3): 17091713 .
[4] Zheng Jinping, Feng Yanjun. Ground pressure behavior of fully mechanized top-coal caving face based on simulation test[J]. Metal Mine, 2013(2): 44-46.

[5] Wang Xiangnan, Cui Ziqiang, Wang Yufeng. Research on weighing feature of repeated mining face in three soft coal seam[J]. Zhongzhou Coal, 2013(8): 23-26.

[6] Zhang Haifeng. Study on mine strata pressure behavior law of irregular fully-mechanized top coal caving mining face in seam shallow depth[J]. Coal Science and Technology, 2015, 43: 45-50.

[7] Yin Xiwen, Zhu Shuancheng, An Ze, et al. Mine strata pressure law of fully mechanized top coal caving mining face in shallow depth and determination of working resistance for powered support[J]. Coal Science and Technology, 2013, 41(5): 50-54.

[8] Bie Xiaofei, Zhai Xinxian, Zhang Shuai. Research on law strata behaviors in ultra thick seam fully-mechanized caving coal face of Qianqiu coal mine[J]. Coal Science and Technology, 2014, 41(Suppl): 80-82.

[9] Liu Yonglu, Liu Jianping, Zhao Wenhua. Characteristics of strata behaviors of fully mechanized top-coal caving face under complex geological conditions[J]. Journal of Mining \& Safety Engineering, 2007, 24(1): 123-126.

[10] Xu Hongjie, Xing Guofu, Xu Tianfa. Abnormal mine pressure behavior and control technology of fully mechanized top coal caving mining face Suancigou mine[J]. Coal Science and Technology, 2012, 40(7).

[11] Xu Qingyun, Huang Guoqing, Li Yongming. Mine strata pressure behavior law of fully mechanized top coal caving mining face during terminal mining period in Buliangou mine $[\mathrm{J}]$. Coal Science and Technology, 2013, 41(6).

[12] Qiao Qiuqiu, Dou Linming, Cen Chuanhong, et al. Analysis on stratapressure behavior at fully-mechanized caving face of deep mine[J]. Coal Mine Safety, 2012, 43(5): 166-169.

[13] Suo Yonglu, Liu Jianping, Wang Lifeng. Characteristics of strata behavior of fully mechanized caving face in soft coal and stable roof condition[J]. Journal of Liaoning Technical University, 2008, 27(5): 641644.

[14] Wang Qingxiong, Ju Jinfeng. Study on mine strata pressure behavior law of $450 \mathrm{~m}$ ultra long fully-mechanized coal mining face[J]. Coal Science and Technology, 2014, 42(3): 125-128.

[15] Yang Yongkang, Li Jiansheng, KANG Tianhe, et al. Effect of working face length on underground pressure characteristics by fully-mechanized top-coal caving mining under shallow-buried

[16] Wang Lujun, Zhu Weibing, Xu Jialin, et al. Study on mine strata pressure behavior law of coal mining face in ultra seam with shallow depth[J]. Coal Science and Technology, 2013, 41(3).

[17] Chen Chong, Yao Enguang, Zhang Zhe. Actual measurement and analysis on behavior rule of pressure of fully-mechanized working face in thin coal seam[J]. Zhongzhou Coal, 2013, (1): 4-7.

[18] Zhao Shengyang, Feng Zengchao, Wang Zhijun. Least energy principle of dynamical failure of rock mass[J]. Chinese Journal of Rock Mechanics and Engineering, 2003, 22(11): 1781-1783. 